\title{
RESEARCH
}

Open Access

\section{Inequities and their determinants in coverage of maternal health services in Burkina Faso}

Takondwa Mwase ${ }^{1 *}$ D, Stephan Brenner ${ }^{1}$, Jacob Mazalale², Julia Lohmann', Saidou Hamadou ${ }^{3}$, Serge M. A. Somda ${ }^{4}$, Valery Ridde ${ }^{5}$ and Manuela De Allegri ${ }^{1}$

\begin{abstract}
Background: Poor and marginalized segments of society often display the worst health status due to limited access to health enhancing interventions. It follows that in order to enhance the health status of entire populations, inequities in access to health care services need to be addressed as an inherent element of any effort targeting Universal Health Coverage. In line with this observation and the need to generate evidence on the equity status quo in sub-Saharan Africa, we assessed the magnitude of the inequities and their determinants in coverage of maternal health services in Burkina Faso.
\end{abstract}

Methods: We assessed coverage for three basic maternal care services (at least four antenatal care visits, facility-based delivery, and at least one postnatal care visit) using data from a cross-sectional household survey including a total of 6655 mostly rural, poor women who had completed a pregnancy in the 24 months prior to the survey date. We assessed equity along the dimensions of household wealth, distance to the health facility, and literacy using both simple comparative measures and concentration indices. We also ran hierarchical random effects regression to confirm the presence or absence of inequities due to household wealth, distance, and literacy, while controlling for potential confounders.

Results: Coverage of facility based delivery was high (89\%), but suboptimal for at least four antenatal care visits (44\%) and one postnatal care visit (53\%). We detected inequities along the dimensions of household wealth, literacy and distance. Service coverage was higher among the least poor, those who were literate, and those living closer to a health facility. We detected a significant positive association between household wealth and all outcome variables, and a positive association between literacy and facility-based delivery. We detected a negative association between living farther away from the catchment facility and all outcome variables.

Conclusion: Existing inequities in maternal health services in Burkina Faso are likely going to jeopardize the achievement of Universal Health Coverage. It is important that policy makers continue to strengthen and monitor the implementation of strategies that promote proportionate universalism and forge multi-sectoral approach in dealing with social determinants of inequities in maternal health services coverage.

Keywords: Maternal health, Inequities, Coverage, Household wealth, Distance, Burkina Faso, Sub-Saharan Africa

\footnotetext{
* Correspondence: takondwa.mwase@uni-heidelberg.de

${ }^{1}$ Institute of Public Health, Faculty of Medicine, Heidelberg University, INF

130.3, Heidelberg, Germany

Full list of author information is available at the end of the article
}

(c) The Author(s). 2018 Open Access This article is distributed under the terms of the Creative Commons Attribution 4.0 International License (http://creativecommons.org/licenses/by/4.0/), which permits unrestricted use, distribution, and reproduction in any medium, provided you give appropriate credit to the original author(s) and the source, provide a link to the Creative Commons license, and indicate if changes were made. The Creative Commons Public Domain Dedication waiver (http://creativecommons.org/publicdomain/zero/1.0/) applies to the data made available in this article, unless otherwise stated. 


\section{Background}

There has been growing concern about inequities in health and health care at global, regional and country levels [1-5]. Evidence demonstrates that the poor and marginalized segments of society have the worst health status, as well as limited access to health enhancing interventions [3, 5-7]. Unfortunately, failure to address equity has been observed to be one of the most serious shortcomings of the Millennium Development Goals (MDGs), particularly of those pertaining to health such as reducing child mortality, improving maternal health, and combating HIV/AIDS, malaria and other diseases [8-11]. Many countries concentrated on reaching targets by acting to reduce mortality and morbidity at the national level, without necessarily addressing inherited inequities in the quest towards universal coverage $[8,12]$. The MDG's unfinished agenda has been picked up by the Sustainable Development Goals (SDGs), a set of goals meant to guide development efforts across sectors up to 2030 [11]. The adoption of Universal Health Coverage (UHC) as one of the targets for SDG 3 - healthy lives and well-being for all - is a very welcome development as equity is implicitly assumed to be included [13]. However, unless equity considerations related to access to and utilization of health care and health outcomes are explicitly accounted for in UHC policies, a risk remains that progress will be made only among the least poor segments of society, widening instead of narrowing the already existing equity gaps [14, 15]. Hence, the United Nations Committee on information and accountability for Women's and Children's Health suggests that indicators for reproductive, maternal and child health should be disaggregated using social stratifiers, such as wealth quintiles, gender, residence (urban/ rural), and education, among others. This is considered essential to adequate monitoring of equitable progress towards achieving the SDG health indicator targets at all levels, from global to regional to country $[2,11]$.

Globally, there has been substantial progress in curbing maternal deaths such that between 1990 and 2015, maternal mortality declined by $44 \%$ [16]. However, maternal mortality still remains unacceptably high, especially in developing countries [16, 17]. The globally declining figures also mask large differences within world regions and country levels [16, 17]. A high burden of maternal mortality is increasingly concentrated in sub-Saharan Africa (SSA). Beyond inequities across countries and regions, important inequities within countries persist, whereby maternal mortality rates among the poor and the least educated women are twice as high as those among the least poor and the more educated women [18]. This situation follows from the fact that in SSA, the rates of skilled birth attendance - identified as the most important factor in reducing maternal deaths and an important element in reducing neonatal deaths
$[19,20]$ - are also five times higher among the non-poor than among the poor [21]. In addition, there are also inequities in focused antenatal care, a service that has proved to provide opportunities for early detection of potential obstetric risks, and that through counseling and education, motivates women to seek skilled attendance at birth $[19,22,23]$. For example, use of at least four antenatal care visits differs by 25 percentage points between both the most and least educated, and the richest and poorest women [24]. Most maternal deaths occur within the first $24 \mathrm{~h}$ after birth [25] and 66\% occur during the first week [26]. However, postnatal care services which could help to avert maternal and neonatal deaths reach even fewer women in SSA than in other world regions: less than half of women receive postnatal care within two days of childbirth, with rates being even lower among the poorer and less educated [27].

Burkina Faso is one of the countries in Sub-Saharan Africa that failed to achieve the target for MDG goal number 5 - reduction of maternal mortality by $75 \%$ between 1990 and 2015 [18]. However, Burkina Faso has made serious efforts towards ensuring equitable access to maternal care services. Several maternal health financing and delivery reforms were developed and implemented, among which are the abolition of user fees for antenatal care (ANC) services in 2002, subsidization of delivery costs for all women by $80 \%$ and by $100 \%$ for the poorest in 2007 , and exemption of the poorest from payment of all user fees for all curative and preventive health services in 2009 [28, 29]. Despite some noticeable decline, the maternal mortality ratio still remains high at 371 per 100,000 live births [30]. Coverage of health services varies greatly across districts and between rural and urban areas [31, 32]. A few studies have investigated determinants of utilization and socioeconomic inequities in using maternal health services. These studies, however, have focused on a few restricted geographical areas and focused only on specific services, failing to address the maternal care continuum and equity [33-35]. Conflicting evidence has emerged with regard to the role of household wealth in determining utilization of maternal health services. One study found that household wealth was negatively associated with utilization of ANC visits [33]. One explanation given for this negative relationship was that poor women might have benefited the most from the new financing policy (i.e. removal of user fees for ANC), while lower ANC utilization among the least poor could be attributed to low value attached to ANC coupled with unwillingness to endure the long waiting times which had resulted from increased utilization after abolition of user fees for ANC [33]. Another study found that household wealth was equity neutral in utilization of at least one ANC visit and facility-based delivery, but was positively and significantly associated with utilization of at least four ANC visits [34]. Inequities in 
utilization of ANC and facility-based delivery services were also found to be negatively associated with distance, animist religion and some ethnicities [33, 34]. As these studies were purely quantitative, they did not offer any explanation for the findings, calling for the application of further qualitative research [33, 34].

This study seeks to fill an existing gap in knowledge by exploring inequities and their determinants in utilization across the maternal care continuum in a large representative sample, including 24 districts in Burkina Faso. By doing so, the study aims at contributing a deeper understanding of whether and what inequities in access to and utilization of maternal care persist in the nation.

\section{Methods}

\section{Study setting}

Burkina Faso is a landlocked, francophone country in West Africa demarcated into 13 regions with 63 districts. In 2016, average life expectancy was estimated at 53.4 years for men and 57.6 years for women. In 2016, about $70 \%$ of the population were estimated to live in rural areas and only $36 \%$ to be literate [36]. Poverty is widespread, with about $41.1 \%$ of the population living below the national poverty line of US $\$ 1.90$ a day [36]. The public health system in Burkina Faso is organized along three levels: primary level (named Centre de Santé et de Promotion Sociale - CSPS) in rural areas some urban areas, secondary level in district capitals and tertiary referral level in regional capitals and in Ouagadougou, the capital city. Total expenditure on health was at 5\% of GDP in 2014 [37]. As noted earlier, Burkina Faso has made access to maternal and child health services one of its key policy objectives. It has done so by introducing a series of reforms, first to reduce (in 2007) and then to remove (in 2016) user fees for maternal care services [38-40]. While it is still early to evaluate the impact of the 2016 policy, evaluations of the 2007 user fee reduction policy indicate equityneutral increases in health service utilization and decreases in out-of-pocket expenditure [41]. This is to say that the 2007 user fee reduction policy neither increased nor decreased existing gaps in service utilization between socio-economic strata, but kept them constant by improving access to care and financial protection across all socio-economic strata.

\section{Data sources}

This study used data from a cross-sectional household survey conducted as part of the baseline assessment of the impact evaluation of a performance-based financing pilot intervention launched in Burkina Faso in 2014. Data was collected between October 2013 and March 2014 in 24 districts (38\% of all districts in the country) on a mainly rural population $(91.8 \%)$ - hence after the 2007 user fee reduction policy, but before the 2016 user fee removal policy. Sampling followed a three-stage clustering procedure. First, clusters were defined according to the catchment areas of 561 primary health facilities in the 24 districts. Second, one village was randomly selected from each cluster. Third, for each sampled village, teams of interviewers drafted a comprehensive list of all households with at least one woman who was either pregnant at the time of the visit or had completed a pregnancy in the prior 24 months. Subsequently, 15 households were to be randomly selected from the list for inclusion in the survey. The final sample included 7844 households, somewhat less than intended as it was not always possible to identify 15 eligible households per sampled village. For this study, we focus on the sub-sample of the 6655 mostly rural and poor women with a completed pregnancy in the prior 24 months residing in the sampled households [42]. However, each of the three outcome variables (i.e.: at least four ANC visits, facility-based delivery and at least one postnatal care) had a different sample size. This was due to the following reasons: i) some women included in the main sample had incomplete pregnancies such as abortions and miscarriages and hence did not attend any of the three maternal health services, and ii) some women attended only one service and not the other services along the continuum of maternal care, and iii) some women might have been missed due to either not completing giving responses to the questionnaire as the survey progressed or due to interviewer mistakes.

The survey questionnaire assessed households' and women's socio-demographic characteristics, and their use of essential maternal health care services during pregnancy (ANC, facility-based delivery, and postnatal care).

\section{Variables and their measurement}

Table 1 provides an overview of all variables included in our analysis, their measurement, and their distribution in the sample.

We defined our primary outcomes to capture coverage along the maternal care continuum, hence we included: a. having attended at least four antenatal care visits (ANC4+); b. having had a facility-based delivery, as a proxy measure for skilled attendance at delivery $[43,44]$; and c. having attended at least one postnatal care visit (PNC1) within six weeks after birth.

Equity is defined as the absence of systematic disparities in health, its social determinants, and/or in health service utilization between more or less disadvantaged social groups $[7,45]$. Inequities exist in the presence of disparities or determinants that are deemed avoidable, unfair and unjust [7]. In this study, equity refers to equal utilization of health services given equal need for such services [7], and when "need" is defined as the capacity 
Table 1 Variables considered in the analyses, their measurement, and distribution in the sample

\begin{tabular}{|c|c|c|}
\hline Variable & Measurement & n (\%) \\
\hline \multicolumn{3}{|l|}{ Outcome Variables $^{a}$} \\
\hline \multirow[t]{2}{*}{ At least 4 ANC $^{\mathrm{b}}$ visits (binary) } & $0=$ Attended less than 4 ANC visits & $3691(55.9)$ \\
\hline & $1=$ Attended at least 4 ANC visits & $2910(44.1)$ \\
\hline \multirow[t]{2}{*}{ Facility-based delivery (binary) } & $0=$ Did not deliver at a facility & $714(10.9)$ \\
\hline & $1=$ Delivered at a facility & $5821(89.1)$ \\
\hline \multirow{2}{*}{$\begin{array}{l}\text { At least } 1 \text { postnatal care visit }(\mathrm{PNC})^{\mathrm{C}} \text { within } \\
\text { six weeks after birth (binary) }\end{array}$} & $0=$ Did not attend $\mathrm{PNC}^{\mathrm{d}}$ & $3067(47.0)$ \\
\hline & $1=$ Attended $\mathrm{PNC1}^{\mathrm{d}}$ & $3459(53.0)$ \\
\hline \multicolumn{3}{|l|}{ Explanatory Variables } \\
\hline \multirow[t]{5}{*}{ Household Wealth Quintiles (categorical) } & $1=$ Poorest & $1315(19.8)$ \\
\hline & 2 & $1267(19.0)$ \\
\hline & 3 & $1291(19.4)$ \\
\hline & 4 & $1352(20.3)$ \\
\hline & 5-Least poor & $1429(21.5)$ \\
\hline \multirow[t]{2}{*}{ Literacy (binary) } & $0=$ Illiterate & $5168(77.7)$ \\
\hline & $1=$ Literate & $1487(22.3)$ \\
\hline \multirow[t]{2}{*}{ Distance of household to catchment facility } & $1=>5 \mathrm{~km}$ & $2651(39.8)$ \\
\hline & $0=\leq 5 \mathrm{~km}$ & $4003(60.2)$ \\
\hline \multirow[t]{2}{*}{ Marital status (binary) } & $0=$ Unmarried & $188(2.8)$ \\
\hline & 1 = Married & $6445(97.2)$ \\
\hline \multirow[t]{4}{*}{ Age (categorical) } & $1=15-20$ years & $1063(16.0)$ \\
\hline & $2=21-29$ years; & $2920(43.9)$ \\
\hline & $3=30-39$ years & $2079(31.3)$ \\
\hline & $4=40+$ years & $585(8.8)$ \\
\hline \multirow[t]{3}{*}{ Religion (categorical) } & $1=$ Christian & $1695(25.5)$ \\
\hline & $2=$ Muslim & $4131(62.1)$ \\
\hline & $3=$ Other & $828(12.4)$ \\
\hline \multirow[t]{3}{*}{ Parity (categorical) } & $1=1$ Pregnancy & $1266(19.4)$ \\
\hline & $2=2-3$ Pregnancies & $2322(35.6)$ \\
\hline & $3=\geq 4$ Pregnancies & $2935(45.0)$ \\
\hline \multirow[t]{3}{*}{ Number of household members (categorical) } & $1=1-3$ Members & $1274(15.2)$ \\
\hline & $2=4-6$ Members & $3212(48.3)$ \\
\hline & $3=7$ Or more members & $2168(32.5)$ \\
\hline
\end{tabular}

${ }^{\mathrm{a}}$ Outcome variables not adding up to $100 \%$ due to missing values as the survey proceeded from one section to the other

${ }^{\mathrm{b}} \mathrm{ANC}=$ Antenatal care; ${ }^{\mathrm{C}} \mathrm{PNC}=$ Postnatal care; ${ }^{\mathrm{d}} \mathrm{PNC} 1=$ at least one postnatal care visit

to benefit from any service along the continuum of maternal health care. The literature recognizes multiple dimensions to equity in health service utilization, such as gender, wealth, education, place of residence/geographic region, ethnicity, age, migratory status, religion, occupation, indigenous status, or sexual orientation [12, 24, 46]. In this study, we investigated inequities in maternal health service coverage along three equity dimensions: i) household wealth; ii) woman's education (measured in relation to literacy); and iii) distance to catchment primary health facility. Household wealth was selected, as overcoming socio-economic inequities in maternal health service coverage remains a top priority for the government and also a priority for the achievement of the SDGs $[28,29,47]$. In order to measure the household wealth, a wealth index using assets and living conditions was developed using the multiple correspondence analysis (MCA) [48]. The following variables were used to compute the household wealth index: housing (type of building materials, number of rooms, water and energy supply sources), assets (TV, radio, fridge etc.), house and fields owned, and animals. After calculation of wealth scores, households were split into quintiles from the poorest (Q1) to least poor (Q5). 
Distance and literacy were chosen because they were identified as important barriers to access by earlier studies $[22,33,34]$. Distance was dichotomized so as to reflect the World Health Organization standard of having a primary health facility within a radius of $5 \mathrm{~km}$ as well as those living outside this recommended World Health Organization $5 \mathrm{~km}$ radius standard. Literacy was used instead of education: although this is recommended for equity analysis, in our sample, less than $1 \%$ of the respondents had formal education. Based on Andersen's behavioral model [49], we included in our analysis a number of additional explanatory variables that were available in our data set as potential relevant confounders. These included: woman's marital status, age, parity, and religion, as well as household size.

\section{Analytical approach}

Our analysis proceeded in steps. First, we looked at the differences in coverage for each of the three outcome variables by districts, and explanatory variables through descriptive bivariate statistics. The chi-square test was used to identify significant associations between the outcomes of interest and selected explanatory variables.

Second, to measure equity, we used simple comparative rates/measures of coverage for two groups [12, 50]. Simple comparative rates/measures draw on data from two subgroups and include differences and ratios to demonstrate absolute and relative inequalities, respectively $[12,46,50,51]$. The absolute gap for socioeconomic inequity was computed by subtracting the outcome of the first quintile from that of the fifth quintile (Q5-Q1) of the respective outcome variable. The ratio of socio-economic inequity was established by dividing the outcome of the fifth quintile to that of the first quintile (Q5/Q1), respectively. Because distance and literacy were binary variables, we computed inequity gap and ratio in the same way as with the continuous variable. It is important to note that absolute measures provide an idea of the actual gap that exists between groups and thus the required effort to close them while relative measures provide an insight into the degree of unfairness between groups [52]. To correct for the weaknesses of the simple comparative rates, especially for socio-economic position (since they only take into account the two extreme groups, leaving out other groups in the middle [53]), we used concentration indices, which are estimated using concentration curves, to draw on data from more than two subgroups [12, 46, 51, 54]. Concentration curves provide a graphical display of the share of health or health services accounted for by cumulative proportions of individuals in a population ranked from poorest to richest at a given point in time $[51,55]$. A concentration curve that lies below the line of equality (45 degrees) signifies presence of inequality favouring the rich, while a curve that lies above the equality line signifies presence of inequality favouring the poor. When it overlaps with the diagonal line (the line of equality), this implies there are no inequalities $[51,55]$. Concentration indices quantify the degree of socioeconomic-related inequality in a given health or health service variable $[51,55]$, defined as twice the area between the concentration curve and the diagonal (line of equality) ranging between -1 and 1. The index takes a negative value when the curve lies above the line of equality, indicating disproportionate concentration of the health or health service variable among the poor and a positive value when it lies above the line of equality, indicating disproportionate concentration of the health or health service variable among the rich and takes the value of zero when there is equality [56].

Third, we ran three separate regressions (one per outcome variable) to confirm the presence or absence of inequities due to household wealth, distance, and literacy, while controlling for all potential confounders. As such, we performed a regression analysis using a hierarchical model to allow for clustering at the district level, attempting to capture the variance in the outcome variables across districts captured by the descriptive analysis. We operationalized our random effects models using Stata version 14 (Stata Corporation, Texas, USA), defining women as first level and district as second level. Our estimated model is of the form:

$$
y_{i j}=\beta_{0 j}+\beta_{j} x_{i j}+u_{j}+\varepsilon_{i j}
$$

where of each observation ' $\mathrm{i}$ ', $\mathrm{Y}$ is one of the 3 outcome variables ' $\mathrm{j}$ ' $[\mathrm{j}=1$ (ANC4+, 2(facility-based delivery), 3 (PNC1)] and $\mathrm{X}$ is the explanatory variables, $\beta_{0 j}$ is the intercept of the respective model for outcome variable ' $j$ ', $u_{j}$ is the district-specific effects, and $\varepsilon_{i j}$ is the error term. As is the case with hierarchical models, our assumption is that each of the levels (districts) has a different (i.e. district-specific) effect $u_{j}$ on the outcome variables $y_{i j}$, which are independent of the explanatory variables $x_{i j}$.

\section{Results}

Table 1 shows the descriptive statistics for all variables included in the analyses. Facility-based delivery had the highest coverage (89\%), followed by use of PNC1 $(53 \%)$. ANC4+ had the least coverage (44.1\%).

Table 2 shows the results of coverage measured by our outcome variables in relation to districts. The results show that there was great variation in the coverage of the three service types across the districts. This ranged from a low of $21 \%$ in Yako in Nord region to a high of $66 \%$ in Tenkodogo in Centre-Est region for ANC4+; from a low of $64 \%$ in Gaoua in Sud-Ouest region to a high of $100 \%$ in Ziniare in Plateau region for facility- 
Table 2 Coverage of ANC4+, facility based delivery and PNC1 by district

\begin{tabular}{|c|c|c|c|c|c|c|}
\hline \multirow[b]{3}{*}{ Total } & \multicolumn{2}{|c|}{ ANC4+ visits } & \multicolumn{2}{|c|}{ Facility based delivery } & \multicolumn{2}{|l|}{ PNC1 } \\
\hline & $(\mathrm{N})$ & $\%$ & $(\mathrm{~N})$ & $\%$ & $\overline{(N)}$ & $\%$ \\
\hline & 6601 & 44.1 & 6535 & 89.1 & 6526 & 53.0 \\
\hline \multicolumn{7}{|l|}{ Region/District } \\
\hline \multicolumn{7}{|c|}{ Boucle du Mouhoun } \\
\hline Boromo & 144 & 48.6 & 143 & 88.1 & 143 & 62.2 \\
\hline Nouna & 542 & 50.4 & 540 & 88.5 & 540 & 51.5 \\
\hline Solenzo & 406 & 46.3 & 402 & 85.1 & 401 & 36.9 \\
\hline Toma & 137 & 45.3 & 135 & 88.1 & 135 & 67.4 \\
\hline \multicolumn{7}{|l|}{ Centre-Sud } \\
\hline Manga & 110 & 45.5 & 110 & 96.4 & 110 & 41.8 \\
\hline \multicolumn{7}{|l|}{ Centre-Est } \\
\hline Ouargaye & 303 & 56.1 & 300 & 96.0 & 296 & 41.2 \\
\hline Tenkodogo & 268 & 66.0 & 268 & 98.9 & 268 & 43.7 \\
\hline Zabré & 38 & 63.2 & 38 & 97.4 & 38 & 44.7 \\
\hline \multicolumn{7}{|l|}{ Centre-Nord } \\
\hline Barsalogho & 59 & 33.9 & 59 & 91.5 & 59 & 59.3 \\
\hline Kaya & 643 & 42.3 & 634 & 85.3 & 634 & 67.0 \\
\hline Kongoussi & 425 & 39.4 & 420 & 94.1 & 419 & 72.1 \\
\hline \multicolumn{7}{|l|}{ Plateau Central } \\
\hline Ziniaré & 252 & 60.3 & 250 & 100 & 250 & 41.2 \\
\hline Boussé & 163 & 38.0 & 162 & 96.3 & 162 & 39.5 \\
\hline \multicolumn{7}{|l|}{ Centre-Ouest } \\
\hline Koudougou & 777 & 48.3 & 769 & 89.3 & 769 & 70.7 \\
\hline Nanoro & 77 & 39.0 & 76 & 89.5 & 76 & 75.0 \\
\hline Réo & 194 & 33.5 & 194 & 85.6 & 194 & 47.4 \\
\hline Sapouy & 249 & 41.4 & 245 & 84.9 & 245 & 52.7 \\
\hline \multicolumn{7}{|l|}{ Nord } \\
\hline Gourcy & 377 & 39.8 & 377 & 95.5 & 377 & 43.8 \\
\hline Ouahigouya & 748 & 33.6 & 734 & 85.3 & 733 & 42.4 \\
\hline Yako & 204 & 20.6 & 203 & 94.1 & 203 & 37.0 \\
\hline \multicolumn{7}{|l|}{ Sud-Ouest } \\
\hline Batié & 116 & 46.6 & 110 & 67.3 & 108 & 46.3 \\
\hline Dano & 55 & 41.8 & 55 & 87.3 & 55 & 67.3 \\
\hline Diébougou & 247 & 41.7 & 244 & 79.1 & 244 & 57.0 \\
\hline Gaoua & 67 & 38.8 & 67 & 64.2 & 67 & 34.3 \\
\hline$P$-value (District) & 0.000 & & 0.000 & & 0.000 & \\
\hline Chi2 test & & & & & & \\
\hline
\end{tabular}

based delivery; and from a low of 34\% in Gaoua in SudOuest region to a high of $75 \%$ in Nanoro in CentreOuest region for PNC1.

Table 3 presents results of service coverage measured by our three outcome variables in relation to our main equity measures and all additional explanatory variables. Bivariate analysis detected few statistically significant differences among subgroups for ANC4+ coverage, but detected many statistically significant differences among subgroups in respect to coverage for facility-based delivery and PNC1. Coverage of ANC4+ was higher among women from least poor households $(p \leq 0.1)$, women who lived near a primary health facility $(p \leq 0.001)$ and women who were literate $(\mathrm{p} \leq 0.1)$. Facility-based delivery and PNC1 were higher among women from the least poor households ( $\mathrm{p} \leq 0.001)$, women living near a primary health facility $(\mathrm{p} \leq 0.001)$ and literate women $(\mathrm{p} \leq 0.001)$.

Table 4 presents the results of inequities related to maternal health service coverage of the three outcome variables measured using simple comparative rates/ measures of coverage. With regard to socio-economic position, the absolute inequity gap in coverage between the least poor (Q5) and the poorest $(\mathrm{Q} 1)$ was widest in PNC1 (10.3 percentage points), followed by facilitybased delivery (8.6 percentage points) and lastly ANC4+ (5.5 percentage points). Coverage was higher among literate women with an absolute gap of 2.7 percentage points for ANC4+, 3.8 percentage points for facilitybased delivery, and 5.7 percentage points for PNC1. Coverage was also higher among women living close to health facilities with an absolute gap of 8 percentage points for ANC4+, 9.9 percentage points for facilitybased delivery and 3.7 percentage points for PNC1. The rate ratios in respect to coverage for the three services and the three equity dimensions are also presented in Table 4. For instance, the results show that coverage of ANC4+ and facility based delivery were 1.1 times higher among the least poor than among the poorest, and 1.2 times higher among the least poor than among the poorest for PNC1. Results further show that coverage of ANC4+ and PNC1 were 1.1 times higher among the literate than among the illiterate; and for facility-based delivery, there were no differences between the literate and the illiterate. With regard to distance, coverage of facility-based delivery and PNC1 were 1.1 times higher among those living near a health facility compared to those living far away, while coverage of ANC4+ was 1.5 times higher among those living near a health facility compared to those living far away.

The concentration indices also confirmed that inequities in coverage between the least poor and the poorest were largest for PNC1 with a value of $0.0415(p<0.001)$, followed by facility-based delivery with a value of 0.0181 $(p<0.01)$. Coverage of ANC4+ displayed the least inequity with a concentration index of $0.0239(p>0.05)$. All indices were positive and statistically significant except for ANC4+ visits, indicating the existence of inequalities along the maternal care continuum in favour of the least poor for PNC1 and facility-based delivery.

Table 5 presents the hierarchical regression analysis results for the three outcome variables. Model 1 confirms 
Table 3 Coverage of ANC4+, facility-based delivery and PNC1 by population subgroups

\begin{tabular}{|c|c|c|c|c|c|c|}
\hline \multirow[b]{3}{*}{ Total } & \multicolumn{2}{|c|}{ ANC4+ } & \multicolumn{2}{|c|}{ Facility-based delivery } & \multicolumn{2}{|l|}{ PNC1 } \\
\hline & $\mathrm{N}$ & $\%$ & $\mathrm{~N}$ & $\%$ & $\mathrm{~N}$ & $\%$ \\
\hline & 6601 & 44.1 & 6535 & 89.1 & 6526 & 53.0 \\
\hline \multicolumn{7}{|c|}{ Household Wealth Quintiles } \\
\hline Poorest & 1307 & 41.6 & 1298 & 84.3 & 1295 & 48.7 \\
\hline 2 & 1250 & 43.6 & 1239 & 88.9 & 1239 & 48.1 \\
\hline 3 & 1278 & 43.1 & 1265 & 88.8 & 1263 & 54.9 \\
\hline 4 & 1346 & 44.5 & 1335 & 90.2 & 1335 & 53.9 \\
\hline Least poor & 1421 & 47.1 & 1398 & 92.9 & 1394 & 58.9 \\
\hline$P$-value & 0.059 & & 0.000 & & 0.000 & \\
\hline \multicolumn{7}{|c|}{ Distance of household to catchment facility } \\
\hline$\leq 5 \mathrm{kms}$ & 3976 & 47.2 & 3937 & 93.0 & 3932 & 54.5 \\
\hline$>5 \mathrm{kms}$ & 2626 & 39.2 & 2598 & 83.1 & 2594 & 50.8 \\
\hline P-Value & 0.000 & & 0.000 & & 0.000 & \\
\hline \multicolumn{7}{|l|}{ Literacy } \\
\hline illiterate & 5127 & 43.4 & 5078 & 88.2 & 5070 & 51.7 \\
\hline literate & 1475 & 46.2 & 1457 & 92 & 1456 & 57.4 \\
\hline P-value & 0.062 & & 0.000 & & 0.000 & \\
\hline \multicolumn{7}{|l|}{ Marital Status } \\
\hline Married & 6393 & 44.3 & 6331 & 89.3 & 6322 & 53.0 \\
\hline Not Married & 188 & 37.2 & 184 & 80.4 & 184 & 54.9 \\
\hline P-value & 0.055 & & 0.439 & & 0.610 & \\
\hline \multicolumn{7}{|l|}{ Age } \\
\hline $15-20$ & 1053 & 43.5 & 1043 & 90.9 & 1043 & 57.9 \\
\hline $21-29$ & 2896 & 44.3 & 2864 & 89.8 & 2861 & 53.1 \\
\hline $30-39$ & 2066 & 44.1 & 2050 & 88.3 & 2047 & 51.8 \\
\hline $40+$ & 580 & 44.1 & 572 & 85.0 & 571 & 48.0 \\
\hline P-value & 0.979 & & 0.001 & & 0.001 & \\
\hline \multicolumn{7}{|l|}{ Parity } \\
\hline 1 & 1255 & 46.8 & 1245 & 92.7 & 1243 & 55.8 \\
\hline $2-3$ & 2305 & 43.4 & 2284 & 89.1 & 2284 & 52.5 \\
\hline$\geq 4$ & 2916 & 43.2 & 2894 & 87.4 & 2889 & 52.3 \\
\hline P-value & 0.079 & & 0.000 & & 0.050 & \\
\hline \multicolumn{7}{|l|}{ Religion } \\
\hline Christian & 1686 & 46.26 & 1671 & 90.0 & 1668 & 57.1 \\
\hline Moslem & 4098 & 43.19 & 4057 & 90.6 & 4052 & 52.1 \\
\hline Other & 818 & 43.77 & 807 & 79.4 & 806 & 49.4 \\
\hline$P$-value & 0.100 & & 0.000 & & 0.000 & \\
\hline \multicolumn{7}{|c|}{ Number of household members } \\
\hline $1-3$ members & 1258 & 44.99 & 1238 & 90.2 & 1237 & 55.1 \\
\hline 4-6 members & 3188 & 43.44 & 3160 & 88.9 & 3156 & 54.1 \\
\hline$\geq 7$ members & 2156 & 44.39 & 2137 & 88.7 & 2133 & 50.2 \\
\hline$P$-value & 0.598 & & 0390 & & 0.006 & \\
\hline Chi2 test & & & & & & \\
\hline
\end{tabular}

the presence of inequities in coverage of ANC4+ linked to household wealth, distance, marital status, parity and religion (these were variables with statistically significant results). Women from the least poor households compared to women from poorest households and women who were married compared to women who were not married were significantly more likely to use ANC4+ visits. Women living further away from a primary health facility compared to women living near a primary health facility, women with 4 or more pregnancies compared to women with one pregnancy and women of Muslim religion compared to women of Christian religion were significantly less likely to use ANC4+ visits.

Likewise, Model 2 confirms the presence of inequities in coverage of facility-based delivery linked to household wealth, distance, literacy, parity and religion (these were variables with statistically significant results). Women from the least poor households compared to women from poorest households and literate women compared to illiterate women were significantly more likely to use facility-based delivery services. High parity (4 or more pregnancies) compared to low parity (one pregnancy), women from other religions compared to Christianity and women living farther away from the primary health facility compared to women living near a primary health facility were significantly less likely to use facility-based delivery services.

Furthermore, Model 3 confirms the presence of inequities in coverage of PNC1 linked to household wealth, distance, age and religion (these were variables with statistically significant results). Women from the least poor households were significantly more likely to use PNC1 than women from the poorest households. Women living farther away from a primary health facility compared to women living near a primary health facility, older women (21-29, 30-39, 40-49 years) compared to young women (15-20 years) and women belonging to other religions compared to Christianity were significantly less likely to attend PNC1.

With rho values of 0.0434 (CI $0.0227-0.0814), 0.1738$ (CI $0.0916-0.3051$ ) and 0.0725 (CI $0.0397-0.1288$ ) at 95\% CI for ANC4+ visits, facility-based delivery and PNC1, respectively, our models confirmed a considerable portion of the observed variation in coverage across districts was attributable to district-level variance. Due to the lack of information on district-level characteristics, we could not attempt to explain this variance.

\section{Discussion}

This study investigated coverage of key maternal health services in respect to inequity and its determinants. The strength of this study lies in the comprehensive equity analysis along the continuum of maternal care services, drawing on a large sample of 6655 mostly rural, poor 
Table 4 Comparison of Inequities in coverage of ANC4+, facility-based delivery and PNC1 along dimensions of Household wealth, Literacy and Distance

\begin{tabular}{|c|c|c|c|c|c|c|c|}
\hline \multirow[t]{4}{*}{ Outcome variable } & \multirow{4}{*}{$\begin{array}{l}\text { Mean } \\
(\%)\end{array}$} & \multicolumn{6}{|c|}{ Health Equity Dimension } \\
\hline & & \multicolumn{2}{|c|}{ Household wealth } & \multicolumn{2}{|l|}{ Literacy } & \multicolumn{2}{|l|}{ Distance $^{a}$} \\
\hline & & $\begin{array}{l}\text { Absolute Difference } \\
\text { (percentage point) }\end{array}$ & Ratio & $\begin{array}{l}\text { Absolute Difference } \\
\text { (percentage point) }\end{array}$ & Ratio & $\begin{array}{l}\text { Absolute Difference } \\
\text { (percentage point) }\end{array}$ & Ratio \\
\hline & & Least poor-Poorest & $\begin{array}{l}\text { Least poor } \\
\text { / Poorest }\end{array}$ & Literate-Illiterate & Literate/ Illiterate & Near-Far & Near/Far \\
\hline ANC4 + visits ${ }^{\mathrm{b}}$ & 44.1 & 5.5 & 1.1 & 2.7 & 1.1 & 8.0 & 1.5 \\
\hline Facility-based delivery & 89.1 & 8.6 & 1.1 & 3.8 & 1.0 & 9.9 & 1.1 \\
\hline $\mathrm{PNC1}^{\mathrm{C}}$ & 53.0 & 10.3 & 1.2 & 5.7 & 1.1 & 3.7 & 1.1 \\
\hline
\end{tabular}

${ }^{\mathrm{a} N e a r}=\leq 5 \mathrm{~km}$ to health facility and Far $=>5 \mathrm{~km}$ to health facility, ${ }^{\mathrm{b}} \mathrm{ANC} 4+=$ at least four antenatal care visits, ${ }^{\mathrm{C} P N C 1}=$ at least one postnatal care visit Basic source: Table 3

women from across 24 districts. This is unique, within and beyond the context of Burkina Faso, given that most existing studies focused more narrowly on just one or two maternal care indicators [33, 34, 57-59] and/or were restricted to specific/single locations [33-35, 38, 39, 60].

Results show that maternal health service coverage in Burkina Faso especially for facility-based delivery was high $(89.1 \%)$, and is one of the few countries in SSA (others being Malawi 89\%, Benin 87\%, Gabon 90\%, and Congo 92\% [61]) to have achieved this high rate. However, coverage remains suboptimal, especially for those maternal health services that require multiple interactions with health care workers, such as ANC4+ (44.1\%). Our findings on ANC4+ coverage of below $50 \%$ are consistent with the 2010 Demographic and Health Survey results on Burkina Faso and in sub-Saharan Africa where only 34 and $50 \%$ of women, respectively attended four or more antenatal visits [62]. PNC1 coverage results from this study are lower than those of the national estimates of $72 \%$ in 2010 [62]. However, this low coverage was consistent with the sub-Saharan African average of $50 \%$ [63].

In addition, our results indicate the persistence of large inequities in coverage across districts, confirming the inequitable patterns in coverage reported in the annual statistical reports compiled using data from the health management information system [31]. Coverage inequities across districts are probably attributable to district-specific characteristics, such as factors related to population density and quality of care on offer, which should be unpacked by future research. What is clear from our analysis, however, is that policies aimed at reducing financial barriers to access, such as user fee removal for ANC in 2002 and subsidies for facility-based delivery in 2007 [64], have not been sufficient to ensure optimal coverage rates nor to compensate for preexisting inequities in coverage across districts. Future research will have to explore whether further steps taken by the government after 2013, such as the introduction of performance-based financing (with systematic targeting and exemption mechanisms for the poor) in 12 districts in 2014 and the full removal of user fees for all care delivered to pregnant and lactating women in 2016, will lead to expected results and be sufficient to close the inequities across districts we observed in our study.

Looking more specifically at the primary objective of our study, i.e. exploring inequities in coverage due to household wealth, distance, and literacy, our findings indicate the persistence of inequities across the entire maternal care continuum for ANC4+, facility-based delivery and PNC1 due to household wealth and distance. Inequities due to literacy were only prevalent in facility-based delivery. Women from the least poor households compared to women from poorest households and women living close to a primary health facility compared to women living farther away from a primary health facility had higher service coverage across all maternal care services. In addition, literate women compared to illiterate women had higher coverage of facility based delivery. Socio-economic inequities have been reported both by earlier studies in Burkina Faso [34, 65] and elsewhere in other developing countries such as Bangladesh [14, 58, 66], Afghanistan [52], India [60], Malawi [67], Ghana [68], Ethiopia [69] and Namibia [53, 70]. In fact, household wealth has been found to be the most crucial factor in determining who receives maternal health services [22, 28, 71]. Interestingly, however, the magnitude of inequalities due to socio-economic position (household wealth) detected in our study is smaller than the one detected in earlier studies and elsewhere in sub-Saharan Africa [65]. For example the absolute gap in $\mathrm{ANC4}+$ coverage between the least poor and the poorest in Burkina Faso Ghana, Cameroon, Senegal, Côte D'Ivoire and Gabon ranged from 23 to 46- percentage points [65], compared to the 5.5 percentage points detected in our study. Similarly, the absolute gap in facility-based delivery coverage between the least poor and the poorest in Burkina Faso Ghana, Cameroon, Senegal, Côte D'Ivoire and Gabon ranged from 20 to 78 percentage points [65], compared to the 8.6 percentage 
Table 5 Determinants of coverage of ANC4+, facility-based delivery and PNC1

\begin{tabular}{|c|c|c|c|c|c|c|}
\hline \multirow[t]{3}{*}{ Variable } & \multicolumn{2}{|l|}{ Model 1} & \multicolumn{2}{|c|}{ Model 2} & \multicolumn{2}{|l|}{ Model 3} \\
\hline & \multicolumn{2}{|l|}{ ANC4+ } & \multicolumn{2}{|c|}{ Facility based delivery } & \multicolumn{2}{|l|}{ PNC1 } \\
\hline & Coefficient & Std Error & Coefficient & Std Error & Coefficient & Std Error \\
\hline \multicolumn{7}{|l|}{ Household wealth Quintiles } \\
\hline \multicolumn{7}{|l|}{ Poorest -Reference } \\
\hline 2 & 0.0510 & $(0.0838)$ & $0.2836^{*}$ & $(0.1274)$ & 0.0628 & $(0.0846)$ \\
\hline 3 & 0.0678 & $(0.0845)$ & $0.2789^{*}$ & $(0.1287)$ & $0.3710^{* * *}$ & $(0.0857)$ \\
\hline 4 & 0.1292 & $(0.0850)$ & $0.4542^{* * *}$ & $(0.1347)$ & $0.3264^{* * *}$ & $(0.0863)$ \\
\hline Least poor & $0.2108^{*}$ & $(0.0859)$ & $0.7819^{* * *}$ & $(0.1455)$ & $0.5312^{* * *}$ & $(0.0882)$ \\
\hline \multicolumn{7}{|l|}{ Literacy } \\
\hline \multicolumn{7}{|l|}{ Illiterate -Reference } \\
\hline literate & 0.1199 & $(0.0638)$ & $0.2665^{* *}$ & $(0.1140)$ & 0.0905 & $(0.065)$ \\
\hline \multicolumn{7}{|l|}{ Distance to catchment facility } \\
\hline \multicolumn{7}{|l|}{$\leq 5 \mathrm{~km}$-Reference } \\
\hline$>5 \mathrm{~km}$ & $-0.3382^{* * *}$ & $(0.0557)$ & $-1.0295^{* * *}$ & $(0.0900)$ & $-0.1598^{* * *}$ & $(0.0567)$ \\
\hline \multicolumn{7}{|l|}{ Marital status } \\
\hline Married & $0.3250^{*}$ & $(0.1620)$ & 0.3418 & $(0.2183)$ & 0.1591 & $(0.0656)$ \\
\hline \multicolumn{7}{|l|}{ Age (years) } \\
\hline \multicolumn{7}{|l|}{ 15-20-Reference } \\
\hline $21-29$ & 0.1513 & $(0.0920)$ & 0.1008 & $(0.1589)$ & $-0.2340^{*}$ & $(0.0941)$ \\
\hline $30-39$ & 0.1768 & (0.1098) & 0.0800 & $(0.1842)$ & $-0.3084^{* *}$ & $(0.1121)$ \\
\hline $40+$ & 0.1812 & $(0.1360)$ & -0.2187 & $(0.2164)$ & $-0.4470^{* * *}$ & $(0.1389)$ \\
\hline \multicolumn{7}{|l|}{ Parity } \\
\hline \multicolumn{7}{|l|}{ Parity $=1$-Reference } \\
\hline Parity $=2-3$ & -0.1232 & $(0.1015)$ & $-0.6130^{* * *}$ & $(0.1808)$ & -0.0419 & $(0.1043)$ \\
\hline Parity $=\geq 4$ & $-0.1649^{*}$ & $(0.1143)$ & $-0.7174^{* * *}$ & $(0.2015)$ & -0.0446 & $(0.1173)$ \\
\hline \multicolumn{7}{|l|}{ Religion } \\
\hline \multicolumn{7}{|l|}{ Christian-Reference } \\
\hline Muslim & $-0.1322^{*}$ & $(0.0658)$ & 0.0063 & $(0.1133)$ & -0.0586 & $(0.0679)$ \\
\hline Other & -0.0031 & $(0.0971)$ & $-0.3395^{* *}$ & $(0.1406)$ & $-0.2877^{* *}$ & $(0.1001)$ \\
\hline \multicolumn{7}{|l|}{ Household Members } \\
\hline \multicolumn{7}{|l|}{ 1-3-Reference } \\
\hline 4-6 members & -0.0546 & $(0.0957)$ & 0.1808 & $(0.1568)$ & 0.0418 & $(0.0981)$ \\
\hline$\geq 7$ members & -0.0390 & $(0.1079)$ & 0.0543 & $(0.1764)$ & -0.1532 & $(0.1104)$ \\
\hline _cons & $-0.4503^{*}$ & $(0.1964)$ & $2.6269^{* * *}$ & $(0.3143)$ & 0.00727 & $(0.2094)$ \\
\hline /Insig2u & -1.9015 & $(0.3412)$ & -0.3680 & $(0.3754)$ & -1.3576 & $(0.3250)$ \\
\hline sigma_u & 0.3865 & $(0.0659)$ & 0.8319 & $(0.1562)$ & 0.5072 & $(0.0824)$ \\
\hline rho & 0.0434 & $(0.0141)$ & 0.1738 & $(0.0539)$ & 0.0725 & $(0.0219)$ \\
\hline LR ratio test of rho, chibar2(01) & $150.65^{* * *}$ & & $140.45^{* * *}$ & & $327.62^{* * *}$ & \\
\hline Wald chi2(19) & $64.74^{* * *}$ & & $223.60 * * *$ & & $103.43^{* * *}$ & \\
\hline
\end{tabular}

${ }^{*} p<0.05 ;{ }^{* *} p<0.01 ;{ }^{* * *} p<0.001$

Standard errors in parenthesis

points detected in our study. This discrepancy between prior findings and our study is probably largely due to the almost complete absence of wealthier urban women from our sample. It could be argued that countries which had similar policies to Burkina Faso of subsidizing deliveries, might have reduced socio-economic inequity gaps even though this led to equity-neutral increases in Burkina Faso as noted earlier. Evidence indicates, 
however, that Ghana which implemented a similar policy at the same time as Burkina Faso, experienced greater inequity in coverage of facility-based deliveries between socio-economic groups [72].

One can therefore safely assume that the differences in magnitude of inequities between earlier studies and our study mainly arise from our sample which, is largely rural and on average is poorer than samples including more urban women, such as those of the Demographic and Health Surveys (DHS). Nevertheless, albeit smaller in terms of absolute magnitude, the inequities in socioeconomic position detected by our analysis are worthy of attention.

Low coverage rates among the poorest women suggest a certain inability on the part of the policies in place to compensate for the disadvantage linked to poverty. This consideration is worrisome given that health outcomes are often at their worst among the poorest population that the literature identified as also having the greatest need $[6,7,73,74]$. It follows that health policies should be specifically targeted to compensate for existing inequities due to socio-economic position by actively encouraging service use among the poorest. Evidence shows that countries that have made rapid progress in maternal health services coverage were those that effectively reached the poorest [15]. Prior research, however, has already indicated that due to an implementation gap in the application of the complete fee exemption for the poorest, the 2007 subsidy for deliveries and obstetric care policy has resulted in an equity-neutral improvement in service use and out-of-pocket spending, but has failed to close existing equity gaps as originally envisioned $[75,76]$. It remains to be seen whether the targeting component (including an exemption mechanism for the poorest) embedded in the abovementioned performance-based financing intervention will be faithfully implemented up to the end of the pilot and result in a reduction in inequities due to socio-economic position [77, 78].

Our findings suggesting that living farther away from a health facility represents an important source of inequity in access for all maternal care services are consistent with earlier studies conducted in Burkina Faso [35, 79] and in Ghana, Nigeria, Sierra Leone $[80,81]$ and Ethiopia [69]. Evidence shows that poor women face several additional barriers in the utilization of maternal health services due to the long distance to health facilities, poor road conditions, absence of a well-organized transport system, and indirect or direct costs associated with transport [22, 82-84].

Similarly, the inequities due to literacy detected in our study are consistent with existing evidence [22, 33-35, $65,71,85]$. Literacy, like education, increases the knowledge of the health benefits of preventive care and awareness of health services, improves the ability of individuals to attain health by influencing their life style, and increases the use of health services through improved knowledge, attitude and practice [59, 71, 86]. Unfortunately, the less educated or illiterate require more education to appreciate the value of health services [43]. Coupled with other challenges such as poverty, maternal health services coverage among the illiterate is generally low [87].

Findings from our regression analysis indicated the role played by an additional set of demand-side factors in shaping service coverage along the maternal care continuum. In line with prior studies [58, 59, 68, 88-93], for instance, we found that parity (having 4 or more pregnancies compared to one pregnancy), marital status (being unmarried compared to being married), and religion (being Muslim as compared to Christian) decreased the likelihood of completing ANC4+ visits. In addition, other traditional religions affected the extent to which facility-based delivery and postnatal care services are being used. Furthermore, parity (having 4 or more pregnancies compared to one pregnancy and age (being older (21-29, 30-39, 40-49 years) compared to being younger (15-20 years) affected the extent to which facility based delivery and PNC1 visit are being used, respectively. These findings are also consistent with some studies conducted in Burkina Faso $[33,35]$ and in other developing countries such as India and Ghana [92, 94] where certain religious groups make less use of certain maternal health services; Ethiopia and Pakistan $[69,95]$ where high number of pregnancies are negatively related to use of certain maternal health services, rural China [96], where higher age is negatively related to use of maternal health services; and rural Vietnam [97], where being unmarried is negatively related to use of certain maternal health services.

Furthermore, our multivariate analysis did not identify literacy as a significant determinant of ANC4+ and PNC1, albeit originally significant in bivariate relationships. This suggests the existence of a probable positive correlation between literacy and household wealth, as noted in prior studies [98]. Still, given that the literature also suggests an independent role of literacy on health outcomes [98]; and given that literacy remained a significant determinant of facility-based delivery, we reiterate the importance for policies to address both socioeconomic and literacy barriers.

In addition, our study used the same set of explanatory variables to estimate the three outcome variable models. Important differences in association between maternal health services and these explanatory variables have been observed. The observed associations differed across the three regression models, indicating that decisions to seek services along the continuum of maternal care are 
shaped by different factors. Thus addressing such determinants of inequities requires a holistic approach along the continuum of maternal health care. In addition, some of these issues are beyond the health sector mandate. These social determinants of health need to be addressed through a multi-sectoral approach in line with the recommendations of the Commission on Social Determinants on Health [5].

To further reduce socio-economic inequities, policy makers could strengthen proportionate universalism -the resourcing and delivering of universal services at a scale and intensity proportionate to the degree of need $[99,100]$. In so doing, services would be universally available, not only for the most disadvantaged, and are able to respond to the level of presenting need [99]. In addition, policymakers could consider introducing new financing and delivery reforms targeting the poorest women, such as conditional cash transfers and vouchers, which have proved to be successful in reducing socioeconomic inequities in the coverage of maternal health services in other countries such as Bangladesh, Kenya, Pakistan, India and Cambodia [44, 66, 95, 101, 102]. Government could further consider strengthening community based outreach services, especially for services like antenatal and postnatal care [24, 103]; and bottom up approaches to identification of health problems and implementation strategies that deal with health problems affecting the poor through community engagement and collaborative research [104-106]; and strengthen health literacy in order to deal with other additional determinants of inequities. This in turn could improve women's knowledge on preventive care benefits, awareness of health service use, lifestyle changes, personal attitudes and practices [86].

In this study, there are a few limitations that must be noted. First, we need to acknowledge that our findings may be affected by recall bias [107, 108], since women were asked to report on service use that could have taken place more than two years prior to the survey date. However, it is unlikely that this had much effect as the interviewers were well trained on how to describe the time period in which this study fell and the interviewers were also looking at the ANC booklets to verify the reported information. Second, the use of facilitybased delivery as a proxy of skilled birth attendance could raise some concerns that the two are not the same. However, it has been found that in developing countries professional/skilled delivery care is nearly synonymous with facility-based care in most countries, with a few exceptions such as Haiti, Indonesia and Madagascar, where home delivery with a professional is relatively common [43]. Third, the measure of socioeconomic position may be called into question - the household asset wealth index not having been very sensitive since this is a rural sample and people are all poor, unlike in a situation whereby the proportion of the least poor in the sample is also large. Evidence shows that in most low-and middle-income countries, households in the wealthiest quintile are often associated with urban areas, such that wealth inequalities are closely associated with urban/rural differences [109]. However, since we detected socio-economic differences in our study, this shows that our measurement was probably sensitive enough. Fourth, there were some, few cases in which residents of Burkina Faso in border districts with Côte D'Ivoire and Ghana obtained maternal health care services from these countries and were just coded by the name of the country without mentioning the type of service used. We treated such cases as seeking maternal health care from the informal sector hence counted as none service use.

\section{Conclusions}

Coverage of facility based delivery in Burkina Faso is very high and comparable to only a few countries in sub-Saharan Africa. However, coverage remains suboptimal for ANC4+ and PNC1 like in many other subSaharan African countries. It is also clear that there is inequality favouring the least poor regarding maternal health service coverage. Thus, in order to achieve UHC, there is a need to review the existing pro-poor strategies and strengthen the development, implementation and monitoring of additional strategies such as those that promote proportionate universalism and bottom up and community engagement and collaborative research. In addition, intensify multi-sectoral approaches and health literacy campaigns in order to overcome other social determinants of inequities in coverage of maternal health services.

\section{Abbreviations}

ANC: Antenatal care; CSPS: Centre de Santé et de Promotion Sociale - CSPS; MDG: Millennium Development Goals; SDG: Sustainable Development Goals; SSA: Sub-Saharan Africa; UHC: Universal Health Coverage; ANC4+: At least 4 antenatal care visits.; PNC1: At least one postnatal care visit; MCA: Multiple Correspondence Analysis; DHS: Demographic Health Surveys

\section{Acknowledgements \\ The authors would like to thank the Programme d'Appui au Développement Sanitaire (PADS) for financial support for data collection given to Centre Muraz. They would also like to thank Aurélia Souares and Hien Herve for successfully coordinating the baseline data collection, and all Muraz interviewers for the extensive fieldwork.}

\section{Funding}

We acknowledge financial support by Deutsche Forschungsgemeinschaft within the funding Programme Open Access Publishing by Baden-Württemberg Ministry of Science, Research and the Arts and by Ruprecht-Karls-Universität Heidelberg.

\section{Availability of data and materials}

The complete datasets are available upon request from http:// microdata.worldbank.org/index.php/catalog/2762. 


\section{Authors' contributions}

TM, MDA and VR conceived the study. JL, MDA, SB, SMAS, and SH contributed to survey design and data collection. TM undertook data analysis with support from JM and MDA. All authors contributed to the interpretation of the results. TM wrote the manuscript with contributions from all authors. All authors read and approved the final manuscript.

\section{Ethics approval and consent to participate}

Ethical clearance for the study was obtained from the Ethical Committee of Heidelberg University (S-272/2013) and from the National Ethics Committee in Burkina Faso ( $N^{\circ} 2013-7-066$ and $\left.N^{\circ} 2015-5-071\right)$.

\section{Consent for publication}

All authors had full access to the data, including statistical reports and tables used in the manuscript and can take responsibility of the integrity of the data and accuracy of the data analysis, and approved the manuscript to be published.

\section{Competing interests}

We used data from the baseline survey of the impact evaluation (IE) of the Performance-Based Financing program in Burkina Faso. The impact evaluation, including data collection for the survey, is funded by the World Bank through the Health Results Innovation Trust Fund (HRITF). None of the authors received any payment by the World Bank for the analysis presented in this manuscript and for the writing. The World Bank did not interfere with design, data analysis, or writing in any way. MDA is the Principal Investigator of the IE, but she receives no salary from the World Bank. TM is a doctoral student at the University of Heidelberg, also not receiving any payment from the World Bank. SB is employed at the University of Heidelberg, partially working on and funded through the above-mentioned IE. $V R$ is also an associated investigator on the $I_{E}$, but receives no payment from the World Bank. SH is a World Bank employee, based in Cameroon.

\section{Publisher's Note}

Springer Nature remains neutral with regard to jurisdictional claims in published maps and institutional affiliations.

\section{Author details}

${ }^{1}$ Institute of Public Health, Faculty of Medicine, Heidelberg University, INF 130.3, Heidelberg, Germany. ${ }^{2}$ University of Malawi, Chancellor College, PO Box 280, Zomba, Malawi. ${ }^{3}$ University of Montreal Public Health Research Institute (IRSPUM), 7101 Avenue de Parc, Room 3060, Montreal QC H3N 1X9, Canada. ${ }^{4}$ Centre MURAZ 2054 Avenue Mamadou KONATE, 01 B.P. 390, Bobo-Dioulasso 01, Burkina Faso. ${ }^{5}$ University of Montreal Hospital Research Centre (CRHHUM), 850 Saint Denis, 3rd Floor, Montreal, QC H2X 0A9, Canada.

\section{Received: 4 December 2017 Accepted: 29 April 2018}

\section{Published online: 11 May 2018}

\section{References}

1. Committee for Development Policy. Implementing the millennium development goals: health inequality and the role of Global Health Partnership. New York: United Nations; 2009.

2. Commission on Information and Accountability for Women's and Children's Health: Keeping promises, measuring results: New York; 2011 (http://www. who.int/topics/millennium_development_goals/accountability_commission/ Commission_Report_advance_copy.pdf. accessed 09 Oct 2017).

3. United Nations. Economic Commission for Africa Centre for Gender and Development. Mainstreaming health equity in the development agenda of African countries. Addis Ababa: UN.ECA; 2008. http://hdl.handle.net/10855/ 15111.

4. Solar O, Irwin A. A conceptual framework for action on the social determinants of health. Social determinants of health discussion paper 2 (policy and practice): WHO; 2010. www.who.int/iris/bitstream/10665/44489/ 1/9789241500852_eng.pdf.

5. Marmot M, Friel S, Bell R, Houwelling TA, Taylor S. Closing the gap in a generation: health equity through action on the social determinants of health. Lancet (London, England). 2008;372:1661-9.

6. Zere E, Mclntyre D. Inequities in under-five child malnutrition in South Africa. Int J Equity Health. 2003;2:7.

7. Whitehead M. The concepts and principles of equity and health. Int J Health Serv. 1992;22:429-45.
8. Waage J, Banerji R, Campbell O, Chirwa E, Collender G, Dieltiens V, Dorward A, Godfrey-Faussett P, Hanvoravongchai P, Kingdon G, et al. The millennium development goals: a cross-sectoral analysis and principles for goal setting after 2015 lancet and London international development Centre commission. Lancet (London, England). 2010;376:991-1023.

9. Scchia SR. Reaching the poor with health, nutrition, and population services: What works, what doesn't, and why. J Epidemiol Commun Health. 2006(9):822.

10. Moser KA, Leon DA, Gwatkin DR. How does progress towards the child mortality millennium development goal affect inequalities between the poorest and least poor? Analysis of demographic and health survey data. BMJ (Clinical research ed). 2005;331:1180-2.

11. World Health Organization. Health in 2015: from MDGs, millennium development goals to SDGs, sustainable development goals. Geneva: World Health Organization; 2015. http://apps.who.int/medicinedocs/en/m/abstract/ Js22230en/.

12. Barros A, Victora C. Measuring coverage in $\mathrm{MNCH}$ : Determing and interpreting inequalities in coverage of maternal, newborn, and child health interventions. PLoS Med. 2013;10

13. Rodney AM, Hill PS. Achieving equity within universal health coverage: a narrative review of progress and resources for measuring success. Int J Equity Health. 2014;13:72.

14. Zere E, Suehiro Y, Arifeen A, Moonesinghe L, Chanda SK, Kirigia JM. Equity in reproductive and maternal health services in Bangladesh. Int J Equity Health. 2013;12:90

15. Victora CG, Barros AJ, Axelson H, Bhutta ZA, Chopra M, Franca GV, Kerber K, Kirkwood BR, Newby H, Ronsmans C, Boerma JT. How changes in coverage affect equity in maternal and child health interventions in 35 countdown to 2015 countries: an analysis of national surveys. Lancet (London, England). 2012;380:1149-56.

16. UNICEF: UNICEF data- monitoring the situation of children and women. 2015.

17. UNICEF, WHO. A decade of tracking progress for maternal, newborn and child survival: the 2015 report. Countdown to 2015: Maternal, Newborn \& Child Survival. 2015; http://41.77.4.165:6510/countdown2030.org/ documents/2015Report/CDReport_2015_ex-profiles_final.pdf.

18. World Health Organization. Trends in maternal mortality: 1990 to 2015: estimates by WHO, UNICEF, UNFPA, World Bank Group and the United Nations population division. Geneva: WHO; 2015.

19. World Health Organization. Reduction of maternal mortality. A joint WHO/ UNFPA/UNICEF/World Bank statement. Geneva: The World Health Organization; 1999.

20. Lawn JE, Cousens S, Zupan J. 4 million neonatal deaths: when? Where? Why? Lancet (London, England). 2005;365:891-900.

21. World Health Organization: Maternal mortality: factsheet N³48 2015. 2015

22. Gabrysch S, Campbell OM. Still too far to walk: literature review of the determinants of delivery service use. BMC pregnancy and childbirth. 2009;9:34.

23. Babalola S, Fatusi A. Determinants of use of maternal health services in Nigeria-looking beyond individual and household factors. BMC pregnancy and childbirth. 2009;9:43.

24. World Health Organization. State of inequality: reproductive, maternal Newborn and child health. Geneva: World Health Organization; 2015.

25. Nour NM. An Introduction to Maternal Mortality. Rev Obstet Gynecol. 2008. $1(2): 77-81$.

26. Nour NM. An introduction to Maternal Mortality. Rev Obstet Gynecol. 2008; $1(2): 77-81$.

27. Lawn JE, Blencowe H, Oza S, You D, Lee AC, Waiswa P, Lalli M, Bhutta Z, Barros AJ, Christian P, et al. Every newborn: progress, priorities, and potential beyond survival. Lancet (London, England). 2014;384:189-205.

28. Belaid $\mathrm{L}$, Ridde $\mathrm{V}$. An implementation evaluation of a policy aiming to improve financial access to maternal health care in Djibo district, Burkina Faso. BMC pregnancy and childbirth. 2012;12:143.

29. Ridde V, Richard F, Bicaba A, Queuille L, Conombo G. The national subsidy for deliveries and emergency obstetric care in Burkina Faso. Health Policy Plan. 2011;26(Suppl 2):ii30-40.

30. World Health Organization: Global Health Observatory data repository. ppswhoint/gho/datal Accessed 04 Dec 20172015.

31. Ministere de la Sante.: Annuare Statistique, Ouagadougou, Burkina Faso, 2014.

32. S.DM S, Millogo JJ, Traore A. A Planification pour une couverture universelle: les resources humaines en sante maternelle, neonatale et infantile au Burkina Faso en 2013-2015. Amsterdam and Ouagadougou: KIT and SERSAP; 2013 
33. De Allegri M, Ridde V, Louis VR, Sarker M, Tiendrebeogo J, Ye M, Muller O, Jahn A. Determinants of utilisation of maternal care services after the reduction of user fees: a case study from rural Burkina Faso. Health policy (Amsterdam, Netherlands). 2011:99:210-8.

34. Rossier C, Muindi K, Soura A, Mberu B, Lankonde B, Kabiru C, Millongo R. Maternal health care utilization in Nairobi and Ougadougou: Evidence from HDSS. Glob Health Action. 2014;7:24351. http://dx.doi.org/10.3402/gha.v7. 24351.

35. Parmar D, De Allegri M, Savadogo G, Sauerborn R. Do community-based health insurance schemes fulfil the promise of equity? A study from Burkina Faso. Health Policy Plan. 2014;29:76-84.

36. indexmundi: Burkina Faso demographics profile 2017.; 2017. http: www. indexmundi,com/burkina_faso/. Accessed 28 Sept 2017

37. World Data Atlas: Burkina Faso - health expenditure - Total health expenditure as a share of GDP; 2017. Available: https://knoemacom/atlas/ Burkina-Faso/topics/Health/Health-Expenditure/Health-expenditure-as-ashare-of-GDP. Accessed 06 Nov 2017

38. Ridde V. Equity and health policy in Africa: using concept mapping in Moore (Burkina Faso). BMC Health Serv Res. 2008;8:90.

39. Ridde V, Kouanda S, Bado A, Bado N, Haddad S. Reducing the medical cost of deliveries in Burkina Faso is good for everyone, including the poor. PLoS One. 2012;7:e33082.

40. Ridde V. From institutionalization of user fees to their abolition in West Africa: a story of pilot projects and public policies. BMC Health Serv Res. 2015;15(Suppl 3):S6.

41. De Allegri M, Ridde V, Louis VR, Sarker M, Tiendrebeogo J, Ye M, Muller O, Jahn A. The impact of targeted subsidies for facility-based delivery on access to care and equity - evidence from a population-based study in rural Burkina Faso. J Public Health Policy. 2012;33:439-53.

42. Institute of Public Health, et al. Impact evaluation for health performancebased financing in Burkina Faso: baseline report: Heidelberg University Germany; 2015. http://microdata.worldbank.org/index.php/catalog/2762.

43. Houweling TA, Ronsmans C, Campbell OM, Kunst AE. Huge poor-rich inequalities in maternity care: an international comparative study of maternity and child care in developing countries. Bull World Health Organ. 2007:85:745-54

44. Rahman S, Choudhury AA, Khanam R, Moin SMI, Ahmed S, Begum N, Shoma NN, Quaiyum MA, Baqui AH. Effect of a package of integrated demand- and supply-side interventions on facility delivery rates in rural Bangladesh: implications for large-scale programs. PLoS One. 2017;12: e0186182.

45. Braveman P, Gruskin S. Defining equity in health. J Epidemiol Community Health. 2003:57:254-8.

46. World Health Organization. National health inequality monitoring: a step-bystep manual. Geneva: World Health Organization; 2017. Licence: CC BY-NCSA $3.01 \mathrm{GO}$

47. PMA2020: SDG-Indicator brief Burkina Faso; 2017. https://pma2020org/sites/ default/files/SDG-Indicator\%20brief\%20Burkina\%20Faso-R2-v2-2017-0503pdf. Accessed on 06 Nov 2017

48. Blasius J, Greenacre M: Multiple correspondence analysis and related methods. 2006.

49. Andersen RM. Revisiting the behavioral model and access to medical care: does it matter? J Health Soc Behav. 1995;36:1-10.

50. Gulliford M. Equity and access to health care. In: Gulliford M, Morgan M, editors. Access to health care. London: Routledge; 2003.

51. Wagstaff A, Paci $P$, van Doorslaer E. On the measurement of inequalities in health. Social science \& medicine (1982). 1991;33:545-57.

52. Akseer N, Bhatti Z, Rizvi A, Salehi AS, Mashal T, Bhutta ZA. Coverage and inequalities in maternal and child health interventions in Afghanistan. BMC Public Health. 2016;16(Suppl 2):797.

53. Zere $\mathrm{E}$, Tumusiime $\mathrm{P}$, Walker $\mathrm{O}$, Kirigia J, Mwikisa C, Mbeeli T. Inequities in utilization of maternal health interventions in Namibia: implications for progress towards MDG 5 targets. Int J Equity Health. 2010;9:16.

54. O'Donnell O, van Doorslaer E, Wagstaff A, Lindelow M. Analysing health equity using household survey data: a guide to techniques and their implementation. Bull World Health Organ. 2008:86(10):816.

55. Kakwani NC. Measurement of tax progressivity: an international comparison. Economic Journal. 1977;87:71-80.

56. Gwatkin DR. How much would poor people gain from faster progress towards the millennium development goals for health? Lancet (London, England). 2005;365:813-7.
57. Pandey S, Karki S. Socio-economic and demographic determinants of antenatal care services utilization in Central Nepal. International journal of MCH and AIDS. 2014;2:212-9.

58. Rahman A, Nisha MK, Begum T, Ahmed S, Alam N, Anwar I. Trends, determinants and inequities of 4+ ANC utilisation in Bangladesh. J Health Popul Nutr. 2017;36:2.

59. Simkhada B, Teijlingen ER, Porter M, Simkhada P. Factors affecting the utilization of antenatal care in developing countries: systematic review of the literature. J Adv Nurs. 2008;61:244-60.

60. Saxena D, Vangani R, Mavalankar DV, Thomsen S. Inequity in maternal health care service utilization in Gujarat: analyses of district-level health survey data. Glob Health Action. 2013;6:1-9.

61. Countdown to 2015: A decade of tracking progress for maternal, , newborn, and child survival: the 2015 report; 2015. Available: http:// countdown2030org/documents/2015Report/Countdown_to_2015_final_ reportpdf. Accessed 02 Nov 2017

62. ICF International: The DHS program STATCompiler; 2012. http:// wwwstatcompilercom Accessed 26 Sept 2017

63. Lawn JE, Blencowe $\mathrm{H}$, Oza S, You D, Lee AC, Waiswa P, Lalli M, Bhutta Z, Barros AJ, Christian P, Mathers C, Cousens SN. Every newborn: progress, priorities, and potential beyond survival. Lancet (London, England). 2014; 384:189-205.

64. Ridde V, Belaid L, Samb OM, Faye A. Health system revenue collection in Burkina Faso from 1980 to 2012. Sante publique (Vandoeuvre-les-Nancy, France). 2014;26:715-25.

65. Countdown to 2015: Maternal, newborn and child Survial: countdown equity analyses by country - 2015; 2015. Available: http:// countdown2030org/documents/2015Equity/2015_CD_equity_profiles_ allpdf. Accessed 02 Nov 2017.

66. Ahmed S, Khan MM. Is demand-side financing equity enhancing? Lessons from a maternal health voucher scheme in Bangladesh. Social science \& medicine (1982). 2011;72:1704-10.

67. Zere E, Moeti M, Kirigia J, Mwase T, Kataika E. Equity in health and healthcare in Malawi: analysis of trends. BMC Public Health. 2007;7:78.

68. Ganle JK, Parker M, Fitzpatrick R, Otupiri E. Inequities in accessibility to and utilisation of maternal health services in Ghana after user-fee exemption: a descriptive study. Int J Equity Health. 2014;13:89.

69. Wado YD, Afework MF, Hindin MJ. Unintended pregnancies and the use of maternal health services in southwestern Ethiopia. BMC international health and human rights. 2013;13:36.

70. Zere E, Oluwole D, Kirigia JM, Mwikisa CN, Mbeeli T. Inequities in skilled attendance at birth in Namibia: a decomposition analysis. BMC pregnancy and childbirth. 2011;11:34.

71. Caliskan Z, Kilic D, Ozturk S, Atilgan E. Equity in maternal health care service utilization: a systematic review for developing countries. International journal of public health. 2015;60:815-25.

72. Dzakpasu S, Soremekun S, Manu A, Ten Asbroek G, Tawiah C, Hurt L, Fenty J, Owusu-Agyei S, Hill Z, Campbell OM, Kirkwood BR. Impact of free delivery care on health facility delivery and insurance coverage in Ghana's Brong Ahafo region. PLoS One. 2012;7:e49430.

73. Gwatkin DR. Health inequalities and the health of the poor: what do we know? What can we do? Bull World Health Organ. 2000;78:3-18.

74. Wagstaff A. Socioeconomic inequalities in child mortality: comparisons across nine developing countries. Bull World Health Organ. 2000;78:19-29.

75. Ridde $\mathrm{V}$, Agier I, Jahn A, Mueller O, Tiendrebeogo J, Ye M, De Allegri M. The impact of user fee removal policies on household out-of-pocket spending: evidence against the inverse equity hypothesis from a population based study in Burkina Faso. The European journal of health economics : HEPAC : health economics in prevention and care. 2015;16:55-64.

76. Ridde V. "the problem of the worst-off is dealt with after all other issues": the equity and health policy implementation gap in Burkina Faso. Social science \& medicine (1982). 2008;66:1368-78

77. Ridde V, Yaogo M, Zongo S, Some PA, Turcotte-Tremblay AM. Twelve months of implementation of health care performance-based financing in Burkina Faso: a qualitative multiple case study. Int J Health Plann Manag. 2017. https://doi.org/10.1002/hpm.2439.

78. Turcotte-Tremblay AM, Gali-Gali IA, De Allegri M, Ridde V. The unintended consequences of community verifications for performance-based financing in Burkina Faso. Social science \& medicine (1982). 2017;191:226-36.

79. Brenner S, De Allegri M, Kambala C, Lohmann J, Moszyk D, Mazalale J, McMahon S. Final results of the RBF4MNH impact evaluation: Heidelberg 
University Germany Institute of Public Health; 2016. http://41.77.4.164:6510/ sphfm.medcol.mw/wp-content/uploads/2016/Final-Report-1.pdf.

80. Thaddeus S, Maine D. Too far to walk: maternal mortality in context. Social science \& medicine (1982). 1994:38:1091-110.

81. Ononokpono DN, Odimegwu CO, Imasiku EN, Adedini SA. Does it really matter where women live? A multilevel analysis of the determinants of postnatal care in Nigeria. Matern Child Health J. 2014;18:950-9.

82. Magadi M, Diamond I, Madise N. Analysis of factors associated with maternal mortality in Kenyan hospitals. J Biosoc Sci. 2001;33:375-89.

83. Essendi H, Mills S, Fotso JC. Barriers to formal emergency obstetric care services' utilization. Journal of urban health : bulletin of the New York Academy of Medicine. 2011;88(Suppl 2):S356-69.

84. Alam N, Chowdhury ME, Kouanda S, Seppey M, Alam A, Savadogo JR, Sia D, Fournier P. The role of transportation to access maternal care services for women in rural Bangladesh and Burkina Faso: a mixed methods study. International journal of gynaecology and obstetrics: the official organ of the International Federation of Gynaecology and Obstetrics. 2016;135(Suppl 1):S45-550.

85. Oumar Mallé S: La gratuité des soins et ses effets sociaux : entre renforcement des capabilités et du pouvoir d'agir (empowerment) au Burkina Faso; 2014 https://papyrusbibumontrealca/xmlui/handle/1866/ 11925. Accessed 29 Nov 2017.

86. Ahmed S, Creanga AA, Gillespie DG, Tsui AO. Economic status, education and empowerment: implications for maternal health service utilization in developing countries. PLoS One. 2010;5:e11190.

87. Gwatkin DR. The need for equity-oriented health sector reforms. Int J Epidemiol. 2001;30:720-3.

88. Alenoghena IO, Isah EC, Isara AR. Maternal health services uptake and its determinants in public primary health care facilities in Edo state, Nigeria. The Nigerian postgraduate medical journal. 2015;22:25-31.

89. Kone-Pefoyo A, Rivard M. Poverty and sociocultural factors in the use of maternal health services in Ivory Coast. Revue d'epidemiologie et de sante publique. 2006;54:485-95.

90. Rashid M, Antai D. Socioeconomic position as a determinant of maternal healthcare utilization: a population-based study in Namibia. Journal of research in health sciences. 2014;14:187-92.

91. Saad-Haddad G, DeJong J, Terreri N, Restrepo-Mendez MC, Perin J, Vaz L, Newby H, Amouzou A, Barros AJ, Bryce J. Patterns and determinants of antenatal care utilization: analysis of national survey data in seven countdown countries. Journal of global health. 2016;6:010404.

92. Addai I. Determinants of use of maternal-child health services in rural Ghana. J Biosoc Sci. 2000;32:1-15.

93. Rurangirwa AA, Mogren I, Nyirazinyoye L, Ntaganira J, Krantz G. Determinants of poor utilization of antenatal care services among recently delivered women in Rwanda; a population based study. BMC pregnancy and childbirth. 2017;17:142.

94. Prakash R, Kumar A. Urban poverty and utilization of maternal and child health care services in India. J Biosoc Sci. 2013;45:433-49.

95. Agha S. Changes in the proportion of facility-based deliveries and related maternal health services among the poor in rural Jhang, Pakistan: results from a demand-side financing intervention. Int J Equity Health. 2011;10:57.

96. Liu X, Gao W, Yan H. Measuring and decomposing the inequality of maternal health services utilization in western rural China. BMC Health Serv Res. 2014;14:102.

97. Duong DV, Binns CW, Lee AH. Utilization of delivery services at the primary health care level in rural Vietnam. Social science \& medicine (1982). 2004:59: 2585-95.

98. Grosse R, Auffrey C. Literacy and health status in developing countries. Annu Rev Public Health. 1989;10:281-97.

99. NHS Health Scotland.: Proportionate universalism and health inequalities; 2014. http://wwwhealthscotlandcom/uploads/documents/24296ProportionateUniversalismBriefingpdf. Accessed 29 Nov 2017.

100. Carey G, Crammond B, De Leeuw E. Towards health equity: a framework for the application of proportionate universalism. Int J Equity Health. 2015;14:81.

101. Quayyum Z, Khan MN, Quayyum T, Nasreen HE, Chowdhury M, Ensor T. "can community level interventions have an impact on equity and utilization of maternal health care" - evidence from rural Bangladesh. Int J Equity Health. 2013;12:22.

102. Pathak PK, Singh A, Subramanian SV. Economic inequalities in maternal health care: prenatal care and skilled birth attendance in India, 1992-2006. PLoS One. 2010;5:e13593.
103. De Brouwere V, Richard F, Witter S. Access to maternal and perinatal health services: lessons from successful and less successful examples of improving access to safe delivery and care of the newborn. Tropical medicine \& international health : TM \& IH. 2010;15:901-9.

104. Oetzel J, Scott N, Hudson M, Masters-Awatere B, Rarere M, Foote J, Beaton A, Ehau T. Implementation framework for chronic disease intervention effectiveness in Maori and other indigenous communities. Glob Health. 2017;13:69.

105. Canadian Institutes of Health Research. Guide to knowledge translation planning at CIHR: integrated and end-of grant approaches. Ottawa: Canadian Institutes of Health Research; 2012.

106. Nilsen P. Making sense of implementation theories, models and frameworks. Implementation science : IS. 2015;10:53.

107. Ansah EK, Powell-Jackson T. Can we trust measures of healthcare utilization from household surveys? BMC Public Health. 2013;13:853.

108. Coughlin SS. Recall bias in epidemiologic studies. J Clin Epidemiol. 1990;43: $87-91$.

109. Filmer D, Pritchett LH. Estimating wealth effects without expenditure dataor tears: an application to educational enrollments in states of India. Demography. 2001;38:115-32.

\section{Ready to submit your research? Choose BMC and benefit from:}

- fast, convenient online submission

- thorough peer review by experienced researchers in your field

- rapid publication on acceptance

- support for research data, including large and complex data types

- gold Open Access which fosters wider collaboration and increased citations

- maximum visibility for your research: over $100 \mathrm{M}$ website views per year

At $B M C$, research is always in progress.

Learn more biomedcentral.com/submissions 